\title{
Evaluation of the Optimum Machining Stability of a Milling Tool with Different Flutes and Overhangs
}

\author{
Yung-Chih Lin ${ }^{1,2}$, Kung-Da Wu' ${ }^{1}$, Wei-Cheng Shih' ${ }^{1}$ Jui-Pin Hung ${ }^{1 *}$ \\ 1 Graduate Institute of Precision Manufacturing, National Chin-Yi University of Technology, Taichung 41170, \\ Taiwan \\ 2 Intelligent Machine Tool Technology Center, Industry Technology Research Institute, Central Region Campus, \\ Taichung 54041, Taiwan \\ * Corresponding author's e-mail: hungjp@ncut.edu.tw
}

\section{ABSTRACT}

In machining practice, the selection of the tooling condition of the cutters is an important task for milling operation with better surface quality and material remove rates. This study was therefore aimed at evaluating the influence of the tooling condition, such as the flutes and overhang length, on the machining efficiency of a milling machine by using the machining stability analysis method. Essentially, the machining stability was calculated based on the measured frequency response functions of the milling cutter, while it was also affected by the changing milling tooling path. Therefore, the machining stabilities in different feeding directions, referred to as polar stability boundary, were evaluated to show the strength and weakness of a specific cutter in contouring machining. The current results show that the overhang length greatly affects the dynamic characteristics and the limited cutting depths of the milling cutter. The stability boundaries of the machining conditions can be enhanced by appropriately adjusting the overhang of the milling cutter. Besides, the 2-flute cutter shows a larger cutting depth for surface contouring as compared to the 4-flute cutter, which is expected to increase the material remove rate under stable machining. As a whole, this study provides valuable references for enhancing the machining efficiency through the use of different tooling conditions.
\end{abstract}

Keywords: machining stability, material remove rate, milling cutter, tooling condition.

\section{INTRODUCTION}

For the purpose of the high speed and precision manufacturing process in various industrial, the machining operations with high remove rate of the workpieces were required. Generally, a high material remove rate was obtained using a milling cutter under high spindle speed, high feeding speed and great cutting depth. Simultaneously, the machining should be conducted under the effective cutting conditions without causing the poor surface roughness or geometry accuracy.

On the other hand, it is a well-known fact that the machining chatter is one of the fatal limitations affecting the material removal rate in milling. As a consequence, lots of studies have been directed to propose the strategies to prevent or suppress chattering. The optimum cutting conditions for improving the material removal rate in milling were selected based on the stability lobes of the specific machine tool [1-4]. In the calculation of the stability lobes diagram, the frequency response function of the cutter is an important variable, which could be obtained from the experimental measurement on milling machine or through the analytical analysis or finite element prediction by means of the model of the spindle system [5-7]. Besides, studies [8-11] showed that the chatter vibration could be caused by dynamic interaction between the work part and the cutting tool in chipping process. Therefore, the factors probably affecting the dynamic behavior or inducing chatter of the milling tool should be taken into consideration when attempting to 
improve the machining productivity by means of the stability lobes.

According to studies [12-14], the vibration characteristic of the milling tool is mainly determined by the spindle dynamics and tool holder with cutter assemble. Different tool holder and tool assembles were found to show different dynamic behaviors, which further affect the ranges of the cutting parameters for stable machining [15-18]. Their results indicate the importance of clarifying the dynamics of the tooling modules before implementation in machining. Besides, due to unsymmetrical features of machine frame structure, the vibration characteristics of the milling tool can also vary with changing of the feeding direction under machining $[5,6]$. Therefore, the variations of the vibration characteristic and hence the machining stability in contouring machining should be taken into account while analyzing the influence of the milling cutter with different tool setting conditions.

In this study, the machining stability theory was applied to evaluate the influence of the tooling conditions on the machining performance based on the experimentally measured frequency response functions of the milling cutters. Additionally, the variations of the machining stability with the feeding direction in X-Y plane machining were analyzed. The optimum cutting depth for stable machining of a milling cutter with different overhang and number of cutting edges can then be presented for further implementation in machining operation.

\section{BASIC THEORY OF MACHINING STABILITY}

For a two-dimensional milling system, the relationship between dynamic cutting forces $\mathrm{F}_{\mathrm{x}}, \mathrm{F}_{\mathrm{y}}$ acting on the cutting edge and the displacements $\Delta \mathrm{x}, \Delta \mathrm{y}$ of the cutter can be expressed as follows according to machining mechanics [11],

$$
\begin{gathered}
\left\{\begin{array}{l}
F_{x} \\
F_{y}
\end{array}\right\}=\frac{1}{2} \mathrm{zK}_{t}\left[\begin{array}{ll}
a_{\mathrm{xx}} & a_{\mathrm{xy}} \\
a_{\mathrm{yx}} & a_{\mathrm{yy}}
\end{array}\right]\left\{\begin{array}{l}
\Delta x \\
\Delta y
\end{array}\right\} \\
\{F(t)\}=\frac{1}{2} \mathrm{zK}_{t}[A(t)]\{\Delta(t)\}
\end{gathered}
$$

in which $[A(t)]$ is the direction coefficients matrix with feeding times. The equation above can be redefined in frequency domain as:

$$
\begin{aligned}
\{r(s)\} & =[G(s)]\{F\} e^{\mathrm{st}} \text { and }\{\Delta(s)\}= \\
& =\left(1 . e^{-\mathrm{sT}}\right) G(s)\{F\} e^{\mathrm{st}}
\end{aligned}
$$

The transfer function between dynamic displacements and cutting forces are:

$$
\Phi_{\mathrm{xy}}=G(s)=\left[\begin{array}{ll}
G_{\mathrm{xx}}(s) & G_{\mathrm{xy}}(s) \\
G_{\mathrm{ys}}(s) & G_{\mathrm{yy}}(s)
\end{array}\right]
$$

The characteristic equation of the cutting systems is:

$$
\begin{aligned}
\{F\} e^{\text {st }}= & \frac{1}{2} z_{0} K_{t}\left[A_{0}\right]\left(1-e^{-\mathrm{sT}}\right) G(s)\{F\} e^{\mathrm{st}} \\
& \operatorname{det}\left([I]+\Lambda\left[\Phi_{\mathrm{xy}}\left(\mathrm{iw}_{c}\right)\right]\right)=0
\end{aligned}
$$

Solution of the characteristic equation can give the complex eigenvalues defined by:

$$
\Lambda=\Lambda_{R}+i \Lambda_{I}=\frac{-N}{4 \pi} z_{0} K_{t}\left(1-e^{-i \omega T}\right)
$$

where: $\Lambda_{R}$ and $\Lambda_{I}$ are real part and imaginary part of the eigenvalues. From (5), the critical axial cutting depth $Z_{\text {lim }}$ and spindle speed $n$ for stable machining can be obtained as follows:

$$
\begin{gathered}
z_{\lim }=\frac{-2 \pi \Lambda_{R}}{\mathrm{NK}_{t}}\left(1+\kappa^{2}\right) \\
\varepsilon=\pi-2 \tan ^{-1} \kappa \\
n=\frac{60 \omega_{c}}{N(2 k \pi+\varepsilon)}, k=\operatorname{lobes}(0,1,2 \ldots)
\end{gathered}
$$

In the equation above, the machining stability can be estimated at different critical vibration mode associated with the spindle tool unit. Normally, these vibration modes dominating the stability are aligned with the principal machine directions $\left(\mathrm{X}_{\mathrm{MT}}, \mathrm{Y}_{\mathrm{MT}}\right)$, such as the yawing vibration of the spindle head about $Y$ axis and the pitching modes about $X$-axis. However, when the cutter is fed in a particular direction, it also could be excited to vibrate under the vibration mode unaligned with the principal natural modes of the spindle tooling system. Under this condition, the frequency response function of the tool tip to the cutting force will be different from those induced in the natural modes of the spindle tool system. This will cause a variation of the machining stability, changing with the feeding directions [6].

Considering this effect, the prediction of the machining stability should be made based on the frequency response function or the transfer function of the tool point displacement to the cutting 
force in the specific feeding direction, rather than that induced in the principal plane. Such transfer function $\Phi_{\text {or }}$ is dependent on the feeding orientation of the cutter, which also governs the chattering of the cutter in terms of the characteristics equation:

$$
\operatorname{det}\left([I]+\Lambda\left[\Phi_{\mathrm{OR}}\left(\mathrm{iw}_{c}\right)\right]\right)=0
$$

The feeding direction dependent transfer function $\Phi_{\text {or }}$ is further determined by the following equation

$$
\left[\Phi_{\mathrm{OR}}\right]=\left[A_{0}\right]\left[\Phi_{\mathrm{uv}}\right]
$$

where $A_{0}$ is the matrix of the average direction factors determined as presented by Altintas et al. [11]. $\Phi_{u v}$ is the transfer function of the displacement to the cutting forces in feeding directions $(u, v)$, which can be related to that defined in the principal direction of the mechanical coordinate system of the machine tool (Figure 1).

$$
\left[\Phi_{u v}\right]=[R]^{-1}\left[\Phi_{\mathrm{xy}}\right][R]
$$

$\Phi_{x y}$ is the transfer function defined in the principal direction. Assume that the principal vibration mode is aligned with the mechanical coordinate system of the milling machine. The vibration of the cutter in this plane can be related to the cutting force.

$$
\left\{\begin{array}{l}
x \\
y
\end{array}\right\}=\left[\begin{array}{ll}
\Phi_{\mathrm{xx}} & \Phi_{\mathrm{xy}} \\
\Phi_{\mathrm{yx}} & \Phi_{\mathrm{yy}}
\end{array}\right]\left\{\begin{array}{l}
F_{x} \\
F_{y}
\end{array}\right\}
$$

In order to obtain the transfer function $\Phi_{u v}$ in the feeding plane, the vibration of the cutter in
$\mathrm{XY}$ plane should be projected onto the feeding plane, that is:

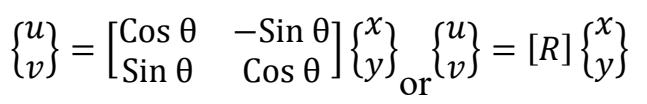

Similarly, the cutting forces can be transferred to the UV plane as:

$$
\left\{\begin{array}{l}
F_{u} \\
F_{v}
\end{array}\right\}=[R]\left\{\begin{array}{l}
F_{x} \\
F_{y}
\end{array}\right\}
$$

Arranging (10)-(12), we have:

$$
\begin{gathered}
\left\{\begin{array}{l}
u \\
v
\end{array}\right\}=[R]\left[\begin{array}{ll}
\Phi_{\mathrm{xx}} & \Phi_{\mathrm{xy}} \\
\Phi_{\mathrm{yx}} & \Phi_{\mathrm{yy}}
\end{array}\right][R]^{-1}\left\{\begin{array}{l}
F_{u} \\
F_{v}
\end{array}\right\} \\
{\left[\Phi_{u v}\right]=[R]^{-1}\left[\Phi_{\mathrm{xy}}\right][R]}
\end{gathered}
$$

Again the solution of the (8) gives the critical axial cutting depth $Z_{\text {lim }}$ and spindle speed $n$ for stable machining in the feeding direction $\theta$. Finally, the critical cutting depth can be expressed as the function of the feeding direction $Z_{\text {lim }}=Z(\theta)$, as shown in Figure 1b.

\section{DYNAMIC CHARACTERISTICS OF MILLING TOOL}

\section{Vibration tests}

As shown in Figure 2, a vertical milling machine (Feeler, VMP 40) was employed for the vibration test, in which two solid carbide cutters (2 and 4 flutes) having $20 \mathrm{~mm}$ diameter and $100 \mathrm{~mm}$ length were respectively installed in tool holder. In the test, the spindle head was positioned at the
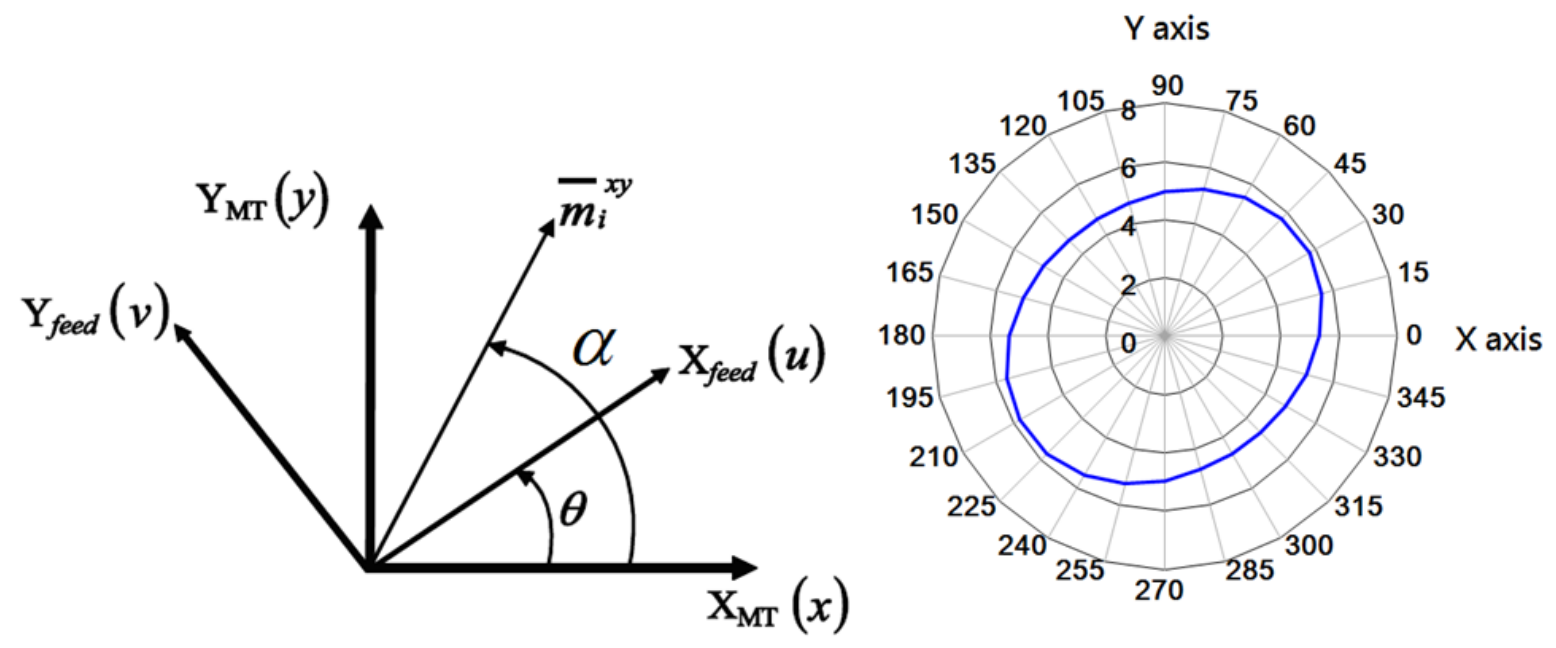

Figure 1. (a) Mechanical coordinate system $\mathrm{X}_{\mathrm{MT}} \mathrm{Y}_{\mathrm{MT}}$ with principal modal vector $m_{i}^{\mathrm{xy}}$ and feeding orientation (u,v) [6]. (b) Polar stability boundary varying with the feeding direction, $Z_{\mathrm{lim}}=\mathrm{Z}(\theta)$ 

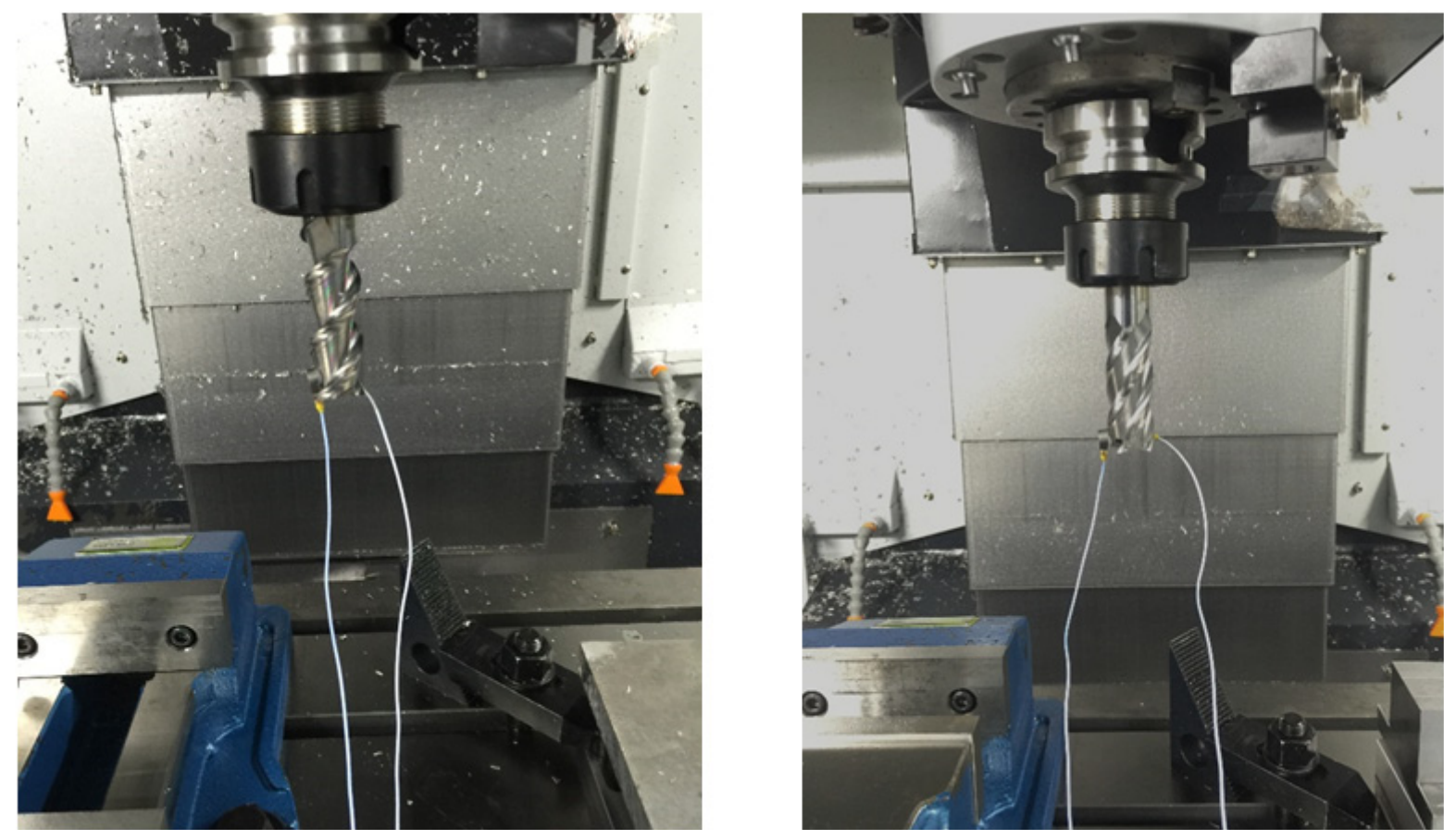

Figure 2. Measurements of tool point frequency response functions of 2 and 4 flute milling cutters by using impact vibration tests

height of $272 \mathrm{~mm}$ from the working table. Two accelerometers were installed on the tool end in the $X$ and $Y$ directions to measure the response excited by the impact hammer applied on the tool end in the opposite side of the sensing point.

Following this procedure, the frequency responses functions of the tool tip measured as $G_{x x}$ and $G_{y x}$, and $G_{x y}$ and $G_{y y}$ were measured, respectively. Here, $G_{x x}^{x y}$ and $G_{v x}^{y y}$ represent the vibration response of the tool in the $X$ and $Y$ directions due to the impact excitation in the $X$ direction. Similarly, $G_{x y}$ and $G_{y y}$ represent the vibration response

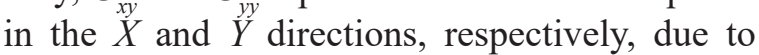
the impact excitation in the $Y$ direction. Besides, in order to quantify the influence of the tooling conditions such as the cutter flutes and overhang length on the dynamic characteristics and machining stabilities, each cutter was fixed in the tool holder with a overhang length of 68,73 and $78 \mathrm{~mm}$, respectively.

\section{Frequency Response Functions at end of milling cutter}

Figure 3 compares the tool point frequency response functions $G_{x x}$ and $G_{y y}$ measured for the 2 and 4 flute cutters of the same overhang length of $68 \mathrm{~mm}$, which are presented in terms of the compliance as a function of the excited frequency. As it is observed in the figure, the two cutters show similar vibration behaviors in the $X$ and $Y$ directions and the vibration peaks occur at the same frequency of $2122 \mathrm{~Hz}$, which is close to natural vibration mode of spindle tool system. In addition, the measured frequency response functions also demonstrate that for both 2 and 4 flute cutters, the dynamic compliances in the $X$ direction are higher than those in the $Y$ direction. This can be ascribed to the fact that the compliance of the milling tool was affected by the machine frame structure. Basically, the C-type milling machine is characterized by the unsymmetrical geometry of the vertical column with spindle head stock in the $X$ and $Y$ axes. Besides, the maximum values of the dynamic compliances of the 2-flute cutter are higher than those of the 4-flute cutter. According to the measured frequency responses, the modal damping ratio associated with dominant mode of the 2 and 4 flute cutters is $1.8 \%$ and $2.7 \%$, respectively. This result indicates that the cutter geometry is probably a factor affecting the damping ratio and hence-thedynamiccompliances of themillingtool.

Regarding the effect of the tool overhang, in the case of the 2-flute cutter, the measured frequency response functions of the tool tip in the $X$ and $Y$ directions are shown in Figure 4. As can be found in these figures, the milling tools with different overhang length show similar dynamic behaviors in the $X$ and $Y$ directions. Again, the dominant mode with peak amplitude occurs at 

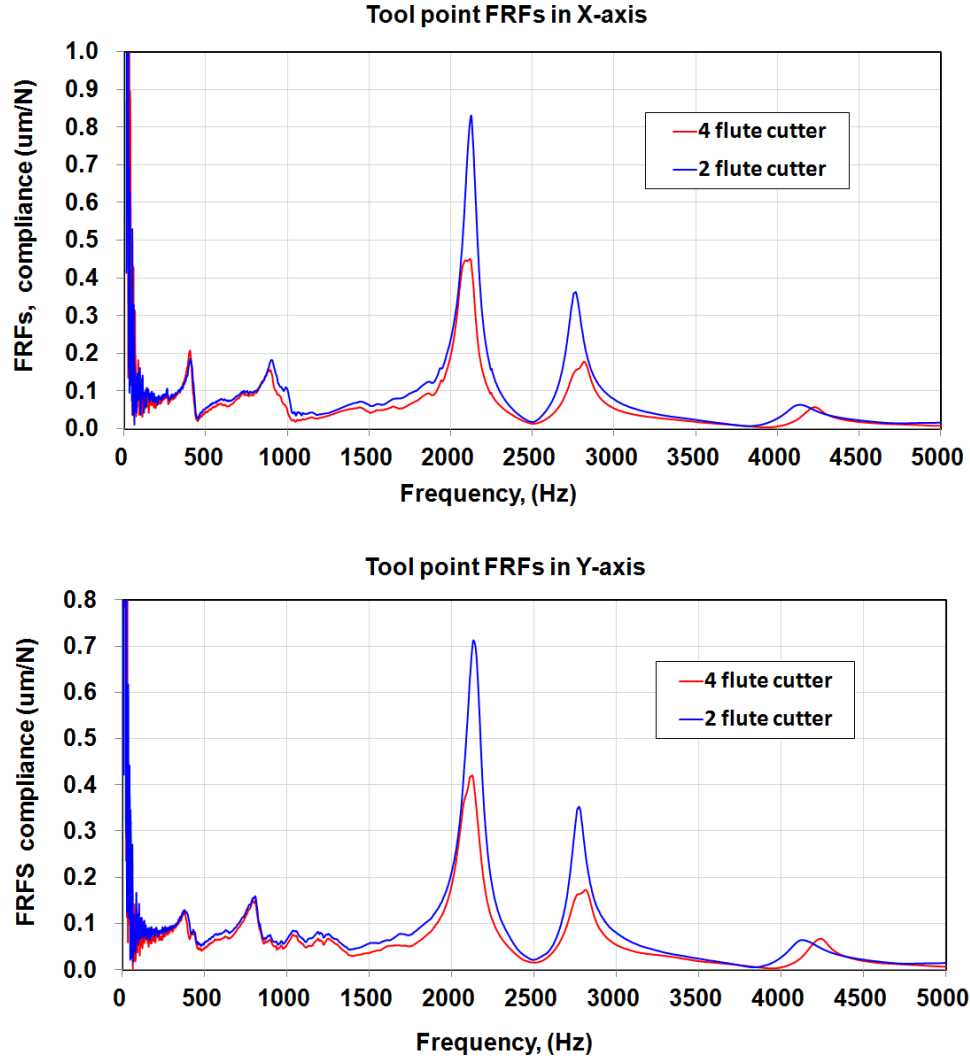

Figure 3. Comparisons of the tool point frequency response functions of milling cutter with 2 and 4 flutes of the same tool length and overhang
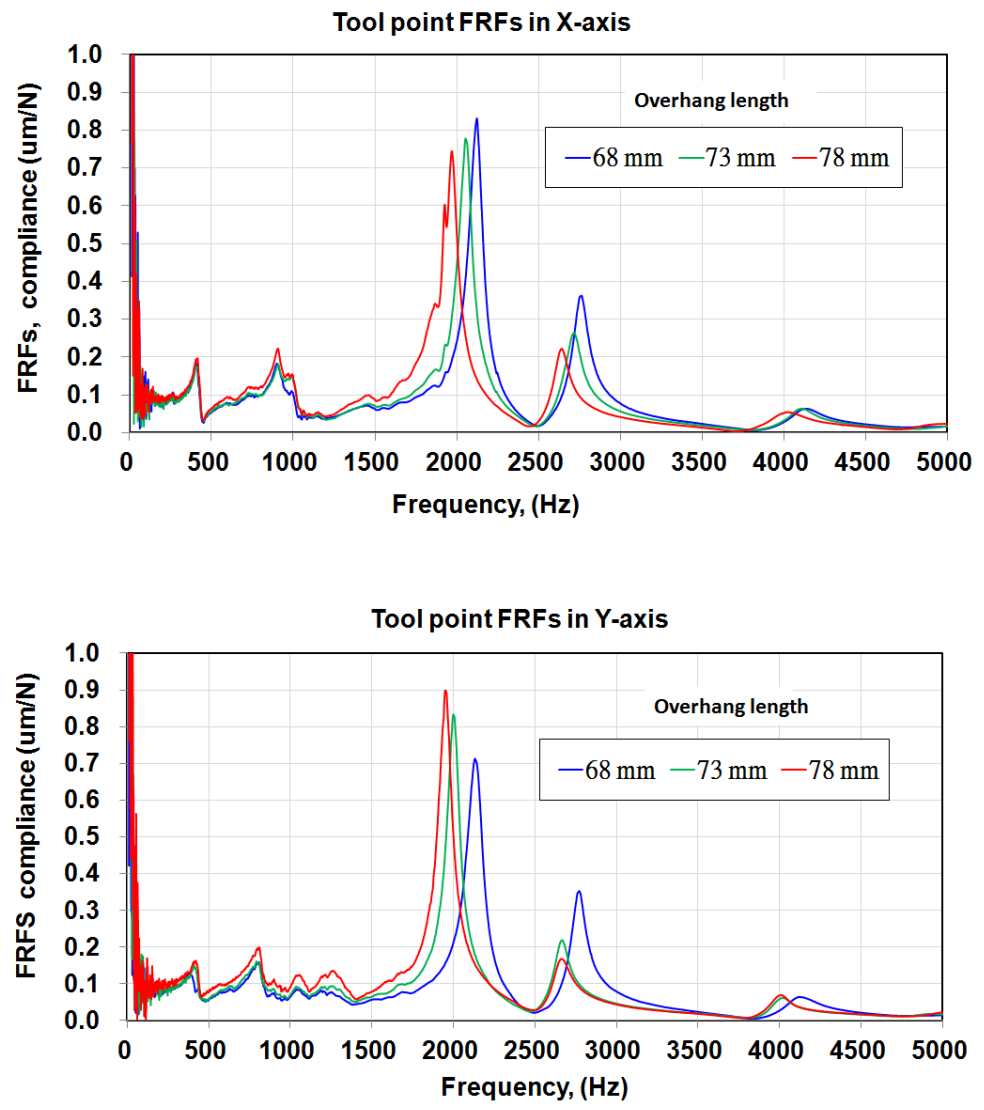

Figure 4. Tool point frequency response functions of 2-flute cutter with different overhang length 
the frequency around 1969-2130 Hz, slightly increasing with the decreasing of the overhang of the cutter. In addition, the maximum compliances in the $X$ and $Y$ directions are about $0.74-0.83 \mu \mathrm{m} / \mathrm{N}$ and $0.70-0.89 \mu \mathrm{m} / \mathrm{N}$, respectively. It was noted that the $X$-axis compliance increases along with the overhang length, but the $Y$-axis compliance decreases in negative way.

\section{DIRECTIONAL DEPENDENT MACHINING STABILITY}

The stock material of Al7075 was used for the calculation of machining stability and the cutting resistance coefficients against carbide cutter were calibrated as $K_{t}=796 \mathrm{~N} / \mathrm{mm}^{2}$ [11]. The measured frequency response functions of the milling cutters with different tooling conditions were served as the input variables for analyzing the machining stability.

\section{Stability lobes diagrams in the $X$ and $Y$ directions}

Figure 5 presents the stability lobes of the 2-flute cutter in the $X$ and $Y$ direction, in which the cutter was inserted in tool holder with overhang length of 68,73 and $78 \mathrm{~mm}$, respectively. As found in the figure, the limited axial machining depth in the $X$-direction is 9.06 , 9.78 and $8.75 \mathrm{~mm}$, but the limited depth in the $Y$ direction is $10.24,8.93$ and $8.57 \mathrm{~mm}$. This result shows that the cutter with long overhang length reduces the machining depth, weakening the cutter performance. This also implies that the machining chatter can be avoided by adjusting the overhang of the cutter. For example, for cutter with overhang $78 \mathrm{~mm}$, when it was operated under spindle speed $6000 \mathrm{rpm}$ and cutting depth $10 \mathrm{~mm}$ (working point $\mathrm{A}$ ), chattering could probably occur since the machining condition was in unstable region. However, if the overhang was adequately shortened by $5 \mathrm{~mm}$ to $73 \mathrm{~mm}$, then the chattering could be avoided because the machining condition fell in the stable region.

Figure 6a compares the $X$ directional stability lobes of the 2 and 4-flute cutters with the same overhang length of $68 \mathrm{~mm}$, respectively. As is found in Figure 7, the 2-flute cutter has a limited axial depth of $9.06 \mathrm{~mm}$, higher than that of 4-flute cutter $(6.96 \mathrm{~mm})$. Similar phenomena were also found in Figure $6 \mathrm{~b}$ for the $Y$ directional stability a)

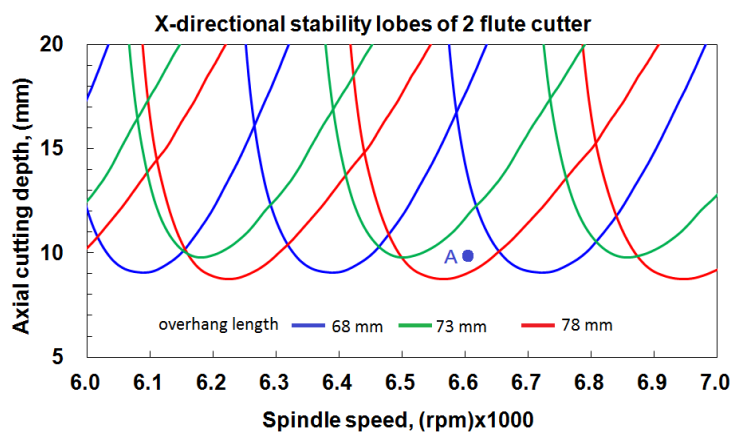

b)

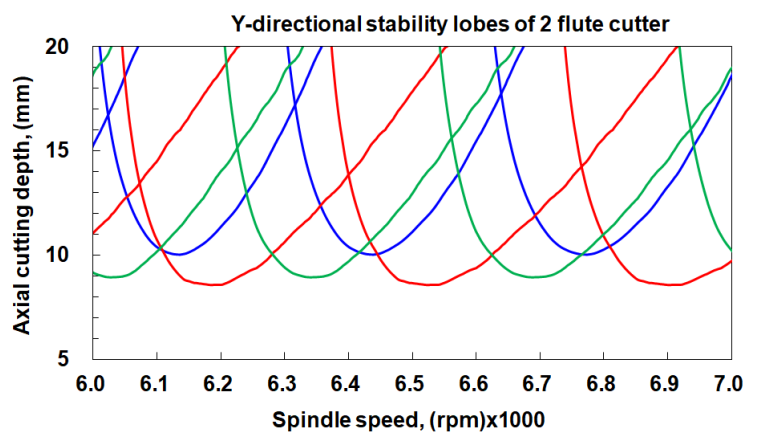

Figure 5. Comparisons of the stability lobes of the 2-flute cutter with different overhang lengths

a)

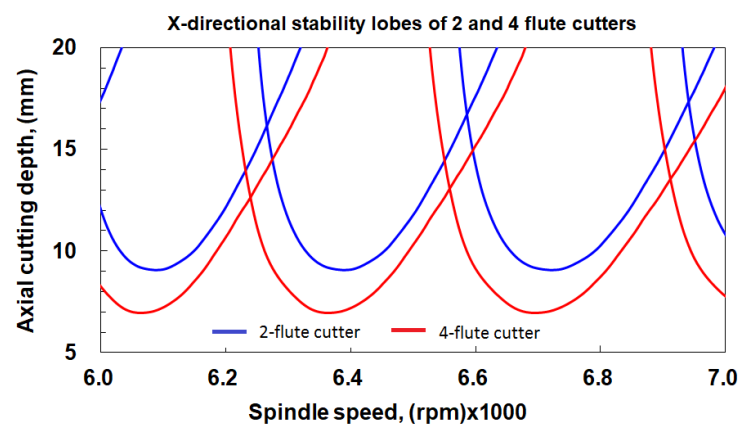

b)

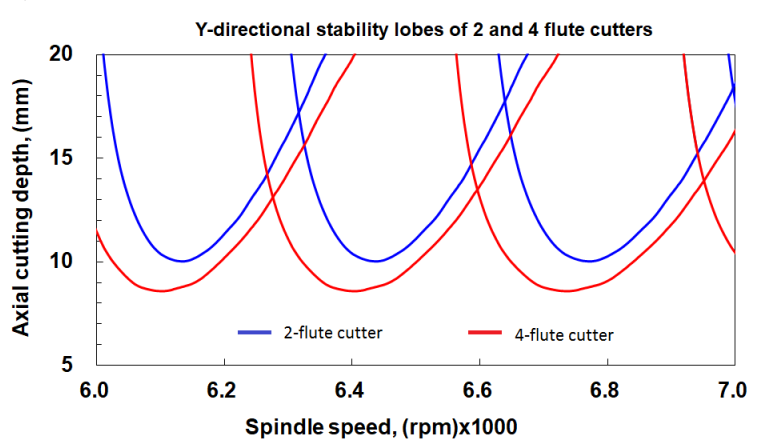

Figure 6. Comparisons of the stability lobes of the 2 and 4-flute cutters 
lobes, the limited depth for 2 and 4-flute cutter is 10.24 and $8.58 \mathrm{~mm}$, respectively. This result shows that the 2-flute cutter shows higher cutting depth for stable machining when compared with the 4 -flute cutter.

\section{Polar stability boundary}

In order to investigate the variations of the machining stability with the changing feeding direction, the limited axial cutting depth for stable machining are depicted in the Figure 7, following the method proposed in Section II. As shown in Figure 7, the limited depths varies with the

a)

Limited cutting depth, (mm) for 2 flute cutter

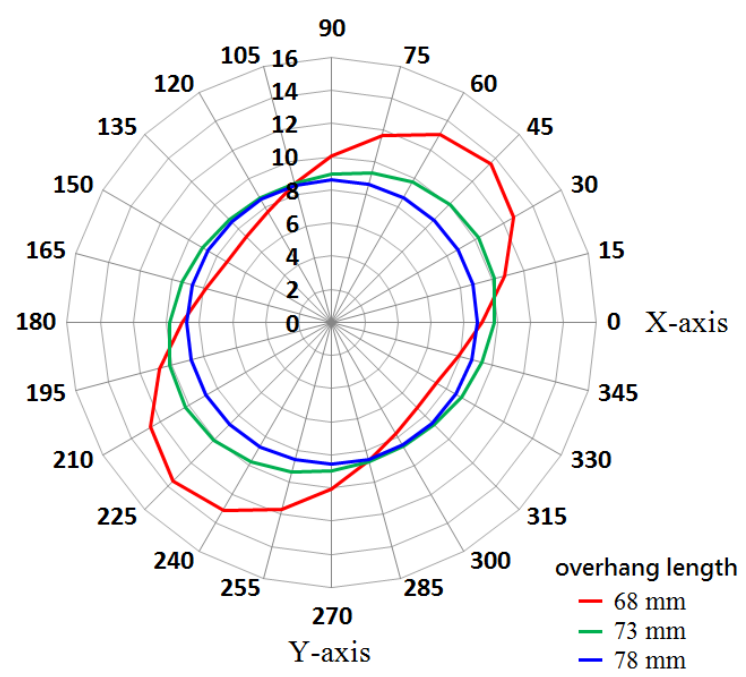

changing of the feeding direction, which is illustrated in an elliptical shaped polar diagram called "polar stability boundary", to describe the relationship between the cutting depth and the feeding direction of the cutter. We can note that the stability boundary changes with cutter flutes and the overhang length of cutter.

In the case of 4-flute cutter with overhang length of $68 \mathrm{~mm}$, as shown in Figure $7 \mathrm{~b}$, the maximum cutting depth occurs in the feeding direction around 60 degrees, about $9.97 \mathrm{~mm}$, while the minimum depth occurs in the direction of 150 degrees, about $6.39 \mathrm{~mm}$. It was noticed that the ratio between the maximum and minimum

b)

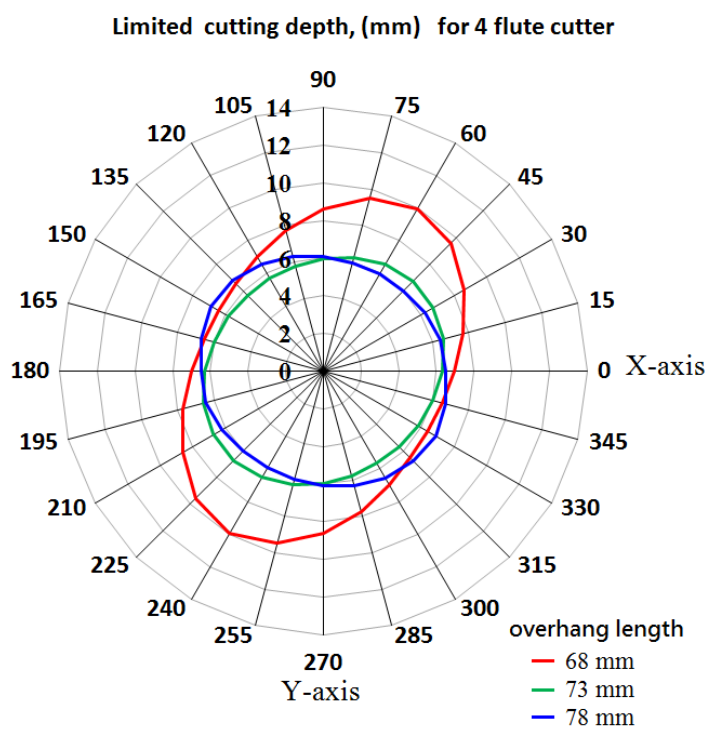

Figure 7. Polar stability boundaries of the 2 and 4-flute cutters with different overhang lengths

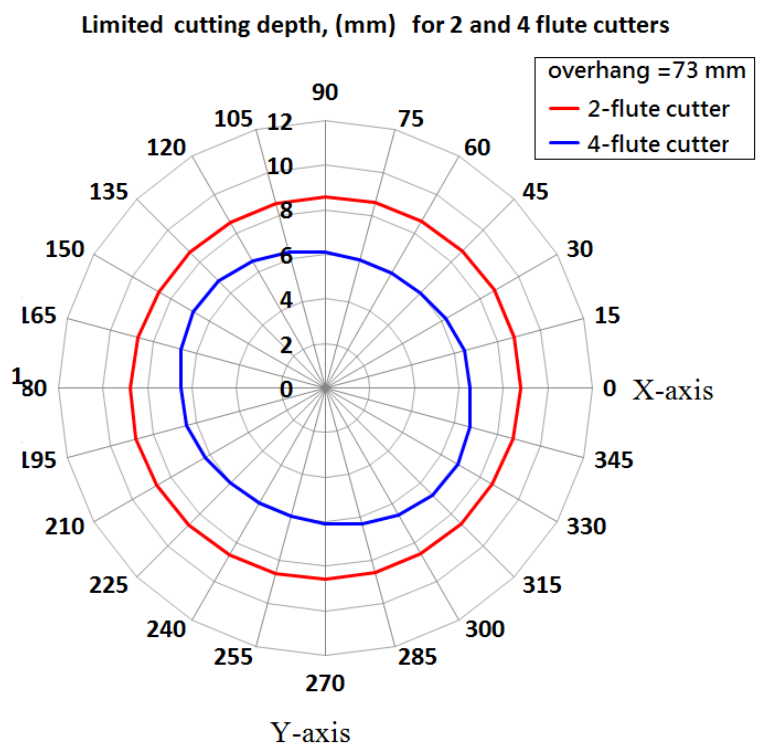

Figure 8. Comparison of the polar stability boundaries of the 2 and 4-flute cutters 
cutting depth is 1.56 , hereby termed as the stability ratio. The stability boundary gives a suggestion that the machining of the cutter with axial depth greater than $6.39 \mathrm{~mm}$ will cause chattering at some certain directions. In contrast, the machining with an axial depth less than $6.39 \mathrm{~mm}$ can be operated without chattering. Therefore, the optimum cutting depth for this cutter in two dimensional contouring without chatter should be $6.39 \mathrm{~mm}$. Figure 7 also suggests that in this study, the cutter with longer overhang length, such as $78 \mathrm{~mm}$, have more consistent limited machining depth in any feeding directions, with stability ratio 1.16 . This shows the effects of the overhang length of cutter on the machining stability of the milling cutter.

Figure 8 further compares the polar stability boundaries of the cutters with 2 and 4-flute with overhang length of $78 \mathrm{~mm}$. From this figure, we can find the maximum depth for stable machining in any feeding direction is about $8.72 \mathrm{~mm}$ for 2-flute cutter and $5.94 \mathrm{~mm}$ for 4-flute cutter. Apparently, the 2-flute cutter provides a wider stability boundary and greater axial depth for stable machining. This implies that the 2-flute cutter can increase the material remove rate, by $47 \%$ when compared with the 4 -flute cutter.

\section{CONCLUSIONS}

This paper investigated the effect on the tooling conditions on the machining stabilities of a milling machine tool. The machining performance of a milling cutter was evaluated in terms of the feeding directional machining stability, which shows the limited cutting depth in different feeding direction in the X-Y plane. The obtained results demonstrate that the stability boundaries and limited axial cutting depth of a specific cutter varied by the flute number and overhang length of the cutter. A longer overhang length of the cutter was found to have more compliance, but with more consistent stability in different feeding directions. The flute of the cutter also affected the stability boundary. When a 2-flute cuter was used, the critical cutting depth could be increased by $47 \%$, as compared with the 4-flute cutter. The results presented in this study provide valuable references for the selection of the tooling conditions for achieving high milling performance.

\section{REFERENCES}

1. Altintas, Y., Lee, P. A general mechanics and dynamics model for helical end mills, CIRP, AnnalsManufacturing Technology, 45(1), 1996, 59-64.

2. Budak, E., Altintas, Y. Analytical prediction of chatter stability in milling, Part II: applications of the general formulation to common milling systems. Journal of Dynamic Systems, Measurement, and Control, 120(1), 1998, 31-36.

3. Smith, S., Tlusty, J. An overview of modeling and simulation of the milling process, Transactions of the ASME Journal of Engineering for Industry, 113(2), 1991, 169-175.

4. Tang, A., Liu, Z. Three-dimensional stability lobe and maximum material removal rate in end milling of thin-walled plate. The International Journal of Advanced Manufacturing Technology, 43(1-2), 2009, 33-39.

5. Hung, J.P., Lai, Y.L., Luo, T.L. and Su, H.C. Analysis of the machining stability of a milling machine considering the effect of machine frame structure and spindle bearings: experimental and finite element approaches, The International Journal of Advanced Manufacturing Technology, 68(912), 2013, 2393-2405.

6. Law, M., Altintas, Y., Phani, A.S. Rapid evaluation and optimization of machine tools with position-dependent stability. International Journal of Machine Tools and Manufacture, 68, 2013, 81-90.

7. Namazi, M., Altintas, Y., Abe, T., and Rajapakse, $\mathrm{N}$. Modeling and identification of tool holderspindle interface dynamics, International Journal of Machine Tools and Manufacture,47(9)(2007) 1333-1341.

8. Tlusty, J., Polacek, M. The stability of machine tools against self-excited vibrations in machining. Trans. ASME, International research in production engineering, 1963, 465-474.

9. Tlusty, J. Dynamics of high-speed milling, Trans. ASME, Journal of Engineering for Industry 108 (2), 1986, 59-67.

10. Tobias, S.A., Fishwick. W. The chatter of lathe tools under orthogonal cutting conditions. Trans. ASME, Journal of Engineering for Industry, 80, 1958, 1079-1088.

11. Altintas, Y., Budak, E., Analytical prediction of stability lobes in milling. CIRP AnnalsManufacturing Technology, 44, 1995, 357-362.

12. Hung, J.P., Chang, Q.W., Wu, K.D., Chen, Y.R. Machining stability of a milling machine with different preloaded spindle. World Academy of Science, Engineering and Technology, International Journal of Mechanical, Aerospace, Industrial, Mechatronic and Manufacturing Engineering, 9(5), 2015, 894-897. 
13. Kivanc, E.B., Budak, E. Structural modeling of end mills for form error and stability analysis. International Journal of Machine Tools and Manufacture, 44(11), 2004, 1151-1161.

14. Kivank, E.B., Budak, E. Modeling statics and dynamics of milling system components. In Proceedings of 36 th CIRP International Seminar on Manufacturing Systems, 2003, 433-440.

15. Tunc, L.T. Prediction of tool tip dynamics for generalized milling cutters using the 3D model of the tool body. The International Journal of Advanced Manufacturing Technology, 95(5-8), 2018, 1891-1909.
16. Grossi, N., Montevecchi, F., Scippa, A., Campatelli, G. 3D finite element modeling of holder-tool assembly for stability prediction in milling. Procedia Cirp, 31, 2015, 527-532.

17. Fleischer, J., Schulze, V., Klaiber, M., Bauer, J., Zanger, F., et al. The influence of tool holder technologies on milling performance. Procedia CIRP, 46, 2016, 226-229.

18. Xuan, X.J., Haung, Z.H., Wu, K.D., Hung, J.P. Prediction of the frequency response function of a tool holder-tool assembly based on receptance coupling method. Engineering, Technology \& Applied Science Research, 8(6), 2018, 3556-3560. 